Journal of Neurology, Neurosurgery, and Psychiatry 1982;45:841-843

Short report

\title{
Polymyalgia rheumatica with diffuse cerebral disease responding rapidly to steroid therapy
}

\author{
S NIGHTINGALE, GS VENABLES, D BATES \\ From the Department of Neurology, Royal Victoria Infirmary, Newcastle upon Tyne, UK
}

SUMMARY A 58-year-old woman presented with the classical features of polymyalgia rheumatica. She also had a global dementia; CT scan and EEG showed diffuse cerebral disease. After steroid treatment, the polymyalgia rheumatica and dementia rapidly resolved and the CT scan and EEG became normal. The inter-relationships of the giant cell arteritides are discussed in the light of this report of the association of polymyalgia rheumatica and steroid-responsive diffuse cerebral disease.

Polymyalgia rheumatica ${ }^{1}$ and cranial arteritis ${ }^{2}$ are syndromes with characteristic clinical features, an elevated erythrocyte sedimentation rate (ESR) and a dramatic response to steroids. Polymyalgia rheumatica may occur before or together with cranial arteritis ${ }^{2-4}$; both conditions are widely regarded as different manifestations of a single pathological process, namely a giant-cell arteritis occurring in the elderly. ${ }^{5}$ Giant-cell arteritis is also a cardinal feature of two other idiopathic disorders, Takayasu's disease $^{6}$ and granulomatous angiitis ${ }^{7-15}$; the arteritis of various systemic disorders such as tuberculosis, sarcoidosis and Hodgkins disease may be associated with giant cells though these are not usually termed "giant-cell arteritis". ${ }^{16}$ The inter-relationship of these arteritides is discussed in the light of our report of the unique association of polymyalgia rheumatica and steroid responsive diffuse cerebral disease.

\section{Case report}

A 68-year-old housewife presented with a 2 year history of progressing dementia and an 8 month history of painful proximal muscle weakness. The mental changes consisted of poor short term memory, confusion and circumlocutory

Address for reprint requests: Dr S Nightingale, Department of Neurology, Royal Victoria Infirmary, Queen Victoria Road, Newcastle upon Tyne. NE1 4LP, UK.

Received 16 February 1982

Accepted 9 April 1982 speech. The proximal muscles were stiff and painful, especially in the morning and she was unable to rise from a chair. Her general health was good and she had not lost weight. She had no history of headache and there was no relevant medical or family history. She had received no medication. Examination revealed a relatively fit looking lady with a persistent low grade pyrexia of $37 \cdot 4^{\circ} \mathrm{C}$. There was no lymphadenopathy, arthritis, skin lesions or signs of cranial arteritis. Her intellect was globally impaired. The cranial nerves were normal. Her proximal muscles were tender and pain restricted testing of muscle strength. The distal muscles appeared normal in strength. Tendon reflexes were brisk and symmetrical; the plantar reflexes were flexor and co-ordination and sensation were within normal limits. Haemoglobin was $11.1 \mathrm{~g} \mathrm{dl}^{-1}$ with normal red blood cell indices. Total white blood count was $6.8 \times$ $10^{9} 1^{-1}$ with a normal differential cell count. The ESR was $80 \mathrm{~mm} \mathrm{hr}^{-1}$. The following investigations were normal: plasma urea, electrolytes, glucose; serum thyroxine, B12, folate and creatine kinase. Liver function was normal, serum auto-antibodies were not detected and serology for syphilis was negative. A chest radiograph was normal and a CT scan (fig A) revealed multiple areas of low density in both cerebral hemispheres especially in the right parietal lobe. The EEG showed a dominant rhythm at $7 \mathrm{~Hz}$ and a fluctuating delta rhythm anteriorly, more marked on the right. The CSF, at $180 \mathrm{~mm}$ pressure, contained no cells, the glucose level was normal and protein was $0.56 \mathrm{gl}^{-1}$ of which $11 \%$ was IgG. The full scale WAIS IQ was 85 (verbal IQ 93; performance IQ 77).

She was treated with prednisone $60 \mathrm{mg}$ daily, her muscle pains resolved within 24 hours and the ESR fell rapidly. Within three days her mental state improved and her temperature returned to normal. Within three weeks she was well in all respects, her haemoglobin had risen to $12 \cdot 2$ 

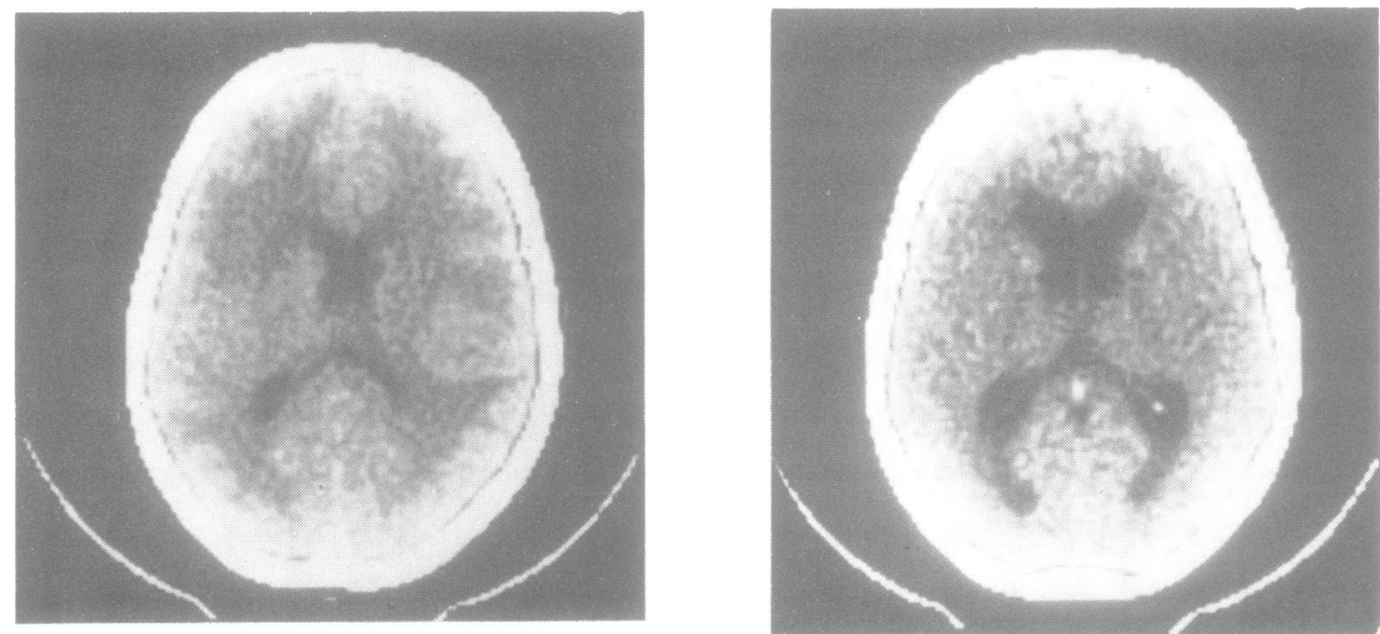

Figure (A)CT scan before treatment showing multiple areas of low density in both hemispheres. (B) Normal CT scan, one month after starting steroid treatment.

$\mathrm{gd} \mathrm{l}^{-1}$, the ESR was $11 \mathrm{~mm} \mathrm{hr}^{-1}$. The CT scan (fig B) and the EEG were normal. Her full scale IQ had risen to 106 (verbal IQ 110; performance IQ 101).

\section{Discussion}

This patient presented with clinical features characteristic of polymyalgia rheumatica, a high ESR, a normal creatine kinase and a dramatic response to steroids. Over the preceding two years she had developed a global dementia. The EEG and CT scan demonstrated diffuse cerebral disease and the CSF protein was mildly elevated. Her mental state, CT scan and EEG rapidly returned to normal following treatment with steroids.

The clinical improvement and resolution of the CT scan appearance with steroid treatment suggests that the cerebral lesions were due to arteritis and cerebral oedema rather than to thrombo-embolic disease. However, cerebral arteritis is not a feature of cranial arteritis or polymyalgia rheumatica. ${ }^{517}$ Although the opthalmological complications of cranial arteritis are due to arteritis of the distal extracranial ophthalmic artery, cerebral complications result from thrombo-embolic disease secondary to more proximal arteritic lesions in the vertebral and carotid arteries. ${ }^{17}$ Since cranial arteritis is thought to be associated with an immune reaction to elastic fibre, ${ }^{18}$ its extracranial distribution may be attributed to the reduced elastic fibre content of intracranial arteries. ${ }^{17}$ Cerebral arteritis may occur in association with various intracranial infections and systemic disorders, including tuberculous meningitis, neurosyphilis, sarcoidosis, yeast and fungal infections, polyarteritis nodosa and Wegener's granulomatosis. ${ }^{19}$ These secondary causes of cerebral arteritis were excluded in our patient by the clinical features, investigations and response to steroids. Widespread cerebral arteritis may also occur as an idiopathic granulomatous angiitis restricted to the cerebral vasculature and we believe that this is the likely diagnosis in our patient.

Granulomatous angiitis is a rare condition characterised by diffuse giant-cell arteritis of the small cerebral vessels, but with no or minimal involvement of the extracranial vessels. ${ }^{7-15}$ The CT scan may show diffuse areas of low density similar to that seen in our patient. ${ }^{13}$ CSF lymphocytosis and a raised CSF protein may be found. ${ }^{1012}$ The condition is seldom diagnosed in life and reports of its treatment are scanty; however some patients have apparently responded to steroids. ${ }^{73}$ The association of polymyalgia rheumatica with granulomatous angiitis previously has not been reported and this association raises the question of the inter-relationship of the giant-cell arteritides. It has been suggested that Takayasu's disease, cranial arteritis and granulomatous arteritis form a spectrum of idiopathic disorders differing only in the size of the vessel involved. ${ }^{711}$ In favour of this concept is the observation that in Takayasu's disease medium sized vessels may be involved as well as the aortic arch, ${ }^{6}$ and also that in cranial arteritis and in polymyalgia rheumatica the aorta may be affected. ${ }^{1320}$ However, most authors have emphasised the distinct clinical and pathological features of these conditions. ${ }^{521}$ The differences between Takayasu's disease and cranial arteritis in respect of age of presentation, site of arterial involvement, type of complication, elevation of ESR and response to steroids have been reviewed 
by Fauci et al..$^{21}$ Cranial arteritis and granulomatous angiitis are distinguished by the size and distribution of the involved arteries. The former characteristically affects the medium sized extradural arteries of the head and neck. ${ }^{17}$ Conversely the latter is almost entirely confined to the cerebral vasculature where it involves the small arteries and venules. Furthermore the older age of presentation, the higher ESR, the normal CSF and the dramatic response to steroids which are seen with cranial arteritis help to distinguish this condition from granulomatous angiitis. These differences argue strongly for considering Takayasu's disease, cranial arteritis and granulomatous angiitis as separate entities. However, compared to Takayasu's disease and cranial arteritis, granulomatous angiitis is an ill-defined clinical syndrome with few constant blood, CSF or radiological findings. It may be the non-specific result of a variety of disease and its occasional association with cranial arteritis, ${ }^{9}$ polymyalgia rheumatica, lymphoma ${ }^{13-15}$ or herpes zoster infections ${ }^{15}$ would support this.

We believe that this particular case is important, not only for the association of polymyalgia rheumatica and cerebral disease, but also because it draws attention to an easily and rapidly reversible cause of dementia. In this respect is it noteworthy that the dementia had progressed for 16 months before the onset of the polymyalgia rheumatica.

We are grateful to $\operatorname{Dr}$ A Appleby for the neuroradiological investigations.

\section{References}

' Hamrin B. Polymyalgia arterica. Acta Med Scand 1972; Suppl 533:4-131.

${ }^{2}$ Paulley JW, Hughes JP. Giant-cell arteritis, or arteritis of the aged. Br Med J 1960;2:1562-7.

${ }^{3}$ Fauchald P, Rygvold O, Oystese B. Temporal arteritis and polymyalgia rheumatica: clinical and biopsy findings. Ann Int Med 1972;77:845-52.

4 Russell RWR. Giant-cell arteritis. A review of 35 cases. $Q J$ Med 1959;28:471-89.

s Goodwin JA. Temporal Arteritis. In: Vinken PJ, Bruyn
GW, eds. Handbook of Clinical Neurology. Vol 39. Amsterdam: North-Holland: 313-42.

${ }^{6}$ Nasu T. Pathology of pulseless disease. A systemic study and critical review of 21 autopsy cases reported in Japan. Angiology 1963;14:225-42.

${ }^{7}$ Castleman B, Towne V. Case records of the Massachusetts General Hospital. Case 43-1976. N Engl J Med 1976;295:944-50.

${ }^{8}$ Cravioto H, Feigin I. Non-infectious granulomatous angiitis with a predilection for the nervous system. Neurology (Minneap) 1959;9:599-609.

${ }^{9}$ Enzmann D, Scott WR. Intracranial involvement of giant-cell arteritis. Neurology (Minneap) 1977;27:794-7.

${ }^{10}$ Kolodny EH, Rebeiz JJ, Caviness VS, Richardson EP. Granulomatous angiitis of the central nervous system. Arch Neurol 1968;19:510-24.

${ }^{11}$ McCormick HM, Neubuerger KT. Giant-cell arteritis involving small meningeal and intra-cerebral vessels. $J$ Neuropathol Exp Neurol 1958;17:471-8.

${ }^{12}$ Nurick S, Blackwood, W, Mair WGP. Giant cell granulomatous angiitis of the central nervous system. Brain 1972;95:133-42.

${ }^{13}$ Rajjoub RK, Wood JH, Ommaya AK. Granulomatous angiitis of the brain: a successfully treated case. Neurology (Minneap) 1977;27:588-91.

14 Rewcastle NB, Tom MI. Non-infectious granulomatous angiitis of the nervous system associated with Hodgkins disease. J Neurol Neurosurg Psychiatry 1962;25:51-8.

is Rosenblum WI, Hadfield MG. Granulomatous angiitis of the nervous system in cases of Herpes zoster and lymphosarcoma. Neurology (Minneap) 1972;22: 348-54.

${ }^{16}$ Boyd W. A textbook of pathology. London: Henry Kimpton, 1970.

17 Wilkinson IMS, Russell RWR. Arteries of the head and neck in giant cell arteritis. A pathological study to show the pattern of arterial involvement. Arch Neurol 1972;27:378-91.

${ }^{18}$ Liang GC, Simkin PA, Mannik M. Immunoglobulins in temporal arteritis. Ann Int Med 1974;81:19-24.

${ }^{19}$ Ferris EJ, Levine HL. Cerebral arteritis: classification. Radiology 1973;109:327-41.

${ }^{20}$ Ostberg G. On arteritis with special reference to polymyalgia rheumatica. Acta Pathol Microbiol Scand 1973;Suppl 237:0-59.

${ }^{21}$ Fauci AS. The spectrum of vasculitis. Clinical, pathologic, immunologic and therapeutic considerations. Ann Int Med 1978;89:660-76. 